\title{
Phase I study of weekly topotecan combined to concurrent external cranial irradiation in adults with glioblastoma multiforme of the brain
}

\author{
H. VARVERIS ${ }^{1}$, E. PETINELLI ${ }^{1}$, J. STRATAKIS ${ }^{2}$ and M. MAZONAKIS ${ }^{2}$ \\ Departments of ${ }^{1}$ Radiotherapy and Oncology, and ${ }^{2}$ Medical Physics, \\ Heraklion University Hospital, Heraklion 711 10, Crete, Greece
}

Received March 23, 2007; Accepted June 20, 2007

\begin{abstract}
Although the standard of care for patients with glioblastoma multiforme (GM) remains postoperative radiotherapy (RT) in combination with chemotherapy (CT), the optimal regimen awaits verification. A phase I study was performed to determine the dose limiting toxicity (DLT) and the maximum tolerated dose (MTD) of topotecan (Hycamptin), given concurrently with RT, in patients with previously untreated glioblastoma multiforme (GM) of the brain. Thirty-six patients with histologically confirmed GM were enrolled. After surgery or stereotactic biopsy, patients received conventional external cranial RT (59.4 Gy/33 fractions in 6.6 weeks). Two cycles of topotecan were administered at days 1 and 4 of each week. Each cycle consisted of 30-min intravenous infusion 30-60 min before $\mathrm{RT}$. The dose of topotecan was escalated in three dose increments from 1.0 to 1.25 and $1.5 \mathrm{mg} / \mathrm{m}^{2}$ on a twice a week schedule among different patient groups. Three dose levels of topotecan were tested. Ten patients accrued to level 1 (topotecan dose $1 \mathrm{mg} / \mathrm{m}^{2} /$ day, twice a week). No grade 4 toxicities were seen. Grade $2 / 3$ hematologic toxicity was observed in 4 patients. Of the 11 patients included at level 2 (topotecan dose $1.25 \mathrm{mg} / \mathrm{m}^{2} /$ day twice a week), 3 presented with grade 3 leucopenia and 2 with grade 3 thrombocytopenia. Of the 15 patients accrued to level 3 (topotecan dose $1.5 \mathrm{mg} / \mathrm{m}^{2}$, twice a week), six had episodes of grade 4 leucopenia and two developed grade 4 thrombocytopenia. No other serious, early non-hematologic or late toxicities were seen at 21 months median follow-up time (range 6-36 months). From the cases included at level 2 and 3 , five patients experienced episodes of grade $2 / 3$ asthenia (13.8\%), headache 9 (25\%), confusion 5 (13.8\%), seizure 4 (11\%), and cutaneous erythema $3(8.3 \%)$. The DLTs of topotecan given concurrently
\end{abstract}

Correspondence to: Dr Harris A. Varveris, Department of Radiotherapy and Oncology, Heraklion University Hospital, P.O. Box 1352, Heraklion 711 10, Crete, Greece

E-mail: varveris@med.uoc.gr

Key words: glioblastoma, radiotherapy, topotecan with RT were mainly hematological and the MTD was determined at the $1.25 \mathrm{mg} / \mathrm{m}^{2} /$ day, twice a week dose level. A phase II chemoradiation study using the above recommended MTD dose of topotecan is ongoing, to establish the response rates, the local failures and the median survival of the above patients.

\section{Introduction}

Glioblastoma multiforme (GM) comprises $21.7 \%$ of primary brain tumors and $47 \%$ of all gliomas (1). Standard treatment for this disease consists of maximal feasible surgical resection combined or not to implantation of carmustine wafers or 5-FU polymers at the time of surgery followed by external radiotherapy (RT) (2).

Median overall survival in patients treated with postoperative RT is around 1 year, with $<10 \%$ surviving 2 years, about $6 \% 3$ years and almost none alive at 5 years (3).

Altered fractionation schemes, interstitial brachytherapy, radiosurgery, 3-D conformal RT, boron neutron capture therapy and proton RT have not led to survival improvement (1).

The addition of adjuvant chemotherapy (CT) to RT improves the 1 year survival by $6 \%$ and offers a 2 -month increase of median survival time (4). Nitrosoureas, especially carmustine (BCNU) are the most active single agents, and no other drug or drug combination has been found to be more effective against GM during the last decade; BCNU was regarded as the benchmark drug with a response rate of 20 $40 \%$ (5). Nevertheless, nitrosoureas have demonstrated modest antitumor activity in the treatment of GM and due to their delayed myelosuppression, the 6-8 week drug-free intervals among CT-cycles may limit their efficacy (6).

Recent studies, particularly the large phase III trial performed by the EORTC and NCI of Canada, presented at the 2004 ASCO Meeting, support the use of RT with concurrent CT, followed by post-RT, CT for patients with GM, using temozolomide (TMZ) (7). However, despite a statistically significant improvement in median survival (15 months for RT+TMZ vs 12 months for RT) and 2-years survival (26 vs $8 \%$ ), better treatments are needed for these tumors.

Other cytotoxic drugs under investigation include inhibitors of topoisomerase I/II (Topo-I/II) and angiogenesis, as well as 
drugs that alter signaling pathways. Camptothecin analogs (topotecan and CPT-11) are believed to exert their cytotoxic and radiosensitizing effects through the inhibition of the nuclear enzyme Topo-I. This enzyme functions to induce transient single strand breaks (SSBs) in the DNA matrix, to allow a DNA strand to uncoil, so that DNA strands rotate around each other, ahead of the replication fork and then reseal leaving the enzyme convalently bound to DNA. DNA uncoils while Topo-I repairs the strand. Topotecan stops Topo-I from repairing the strand in one spot and while DNA starts to divide, the drug-induced damage prevents completion of DNA replication. Subsequent interactions of the covalent Topo-I-DNA complexes with moving DNA replication forks lead to irreversible fork arrest. These events lead to the conversion of repairable SSBs of DNA into Double Strand Breaks (DSBs), i.e. irreparable lethal damage of DNA followed by cell death and cell apoptosis (8).

Topotecan has been considered a promising CT-agent for treatment of brain tumors for its ability i) to penetrate the Blood-Brain Barrier; Blaney et al reported good CNS penetration of topotecan in primates with maximum doses 30 min after a rapid i.v. infusion (9). ii) To be administered on a more frequent basis because it produces less durable myelo-suppression compared to nitrosureas (BCNU alone or the PCV regimen) (1). iii) For its preclinical activity (tumor regression and growth delay) against xenografts derived from ependymomas, pediatric and adult high-grade gliomas and medulloblastomas (10). iv) For its clinical activity in treating patients with GM and recurrent GM $(11,12)$. v) For its antitumor activity against other solid tumors (13) such as ovarian cancer, hematologic malignancies, SCLC, NSCLC, prostate cancer, soft tissue sarcoma, and metastatic melanoma, and vi) for its radiosensitizing properties in vitro and in vivo (14). This radiosensitization seems to be schedule dependent, Sphase specific, cell-line dependent, and not directly related to drug cytotoxicity; it was shown that the potentiation of RT exposure by topotecan was maximal when the drug was administered 2-4 h before RT (15). Due to limiting but encouraging data regarding the radiosensitizing properties of topotecan, in July 2001, we started a phase I/II study to establish the dose limiting toxocities (DLTs) and the maximum tolerated dose (MTD) of topotecan given concurrently with conventional external RT, for patients with GM of the brain. A secondary objective was to determine the acute/late toxicities of the above chemoradiation treatment, as well as the response rates, disease-free and overall survival for these patients.

\section{Patients and methods}

A phase I/II trial was undertaken, approved by the research ethics committee of the Heraklion University Hospital, and the Medical School of the University of Crete, Greece.

Patients with histologically documented GM after surgery or stereotactic biopsy, with no prior RT or CT were eligible for the study. Other inclusion criteria were age 21-76 years, performance status (WHO) 0-2, hemoglobin $(\mathrm{Hb})>12.5 \mathrm{~g} / \mathrm{dl}$, white blood count (WBC) $>4,000 / \mu 1$, absolute neutrophil count $(\mathrm{ANC})>2,200 / \mu 1$, platelets $(\mathrm{PTL})>120,000 / \mu 1$, normal liver, renal and cardiac function, measurable disease on MRI scan, absence of a second primary tumor, and a written informed consent. Patients with major heart, lung, renal or psychiatric disease were excluded.

Pretreatment and treatment evaluation. These include a detailed medical history and physical examination, full blood cell count (FBC), complete blood chemistry, ECG, heart ultrasound test, chest X-ray and an MRI scan of the brain. FBCs, liver function tests (LFTs), serum urea, creatinine and ECG were performed once weekly during RT. Hematologic toxicity was followed with weekly FBCs and differential PTL counts. For grade 2-4 sequelae (WBC: 2.0-2.9, 1.0-1.9, $<1.0 \mathrm{~K} / \mu 1$; ANC: $1.0-1.2,0.5-0.9,<0.5 \mathrm{~K} / \mu 1$; PTL: 50.0-74.9, $25.0-49.9,<25.0 \mathrm{~K} / \mu 1$ ) respectively, daily counts until recovery were used. LFTs, complete biochemical profile, ECG, and a detailed toxicity questionnaire (headache, nausea, fever, confusion, seizures, insomnia, anorexia, altered taste, diarrhea, asthenia) were performed every week. Chemoradiation sequelae were recorded according to the NCI and RTOG Common Toxicity Criteria for CT and RT (16). Every other week during the treatment period, patients underwent clinical and neurological examinations, mental status, anticonvulsant levels and assessment of WHO performance status as well as estimation of the doses of corticosteroids and anticonvulsants. At month 1 and every third subsequent month post treatment, the same parameters were evaluated until tumor progression. MRI scans with contrast medium were performed at 3-month intervals after RT and repeated at the time of neurologic deterioration.

Treatment. Seven (19.4\%) patients had undergone gross total resections, 18 (50\%) partial resections and 11 had stereotactic biopsies (Table I).

All patients received extenal RT with two Linacs (The 6 MV SL 75-5, Philips SA, West Sussex, UK and the $6 \& 18$ MV Primus of Siemens, Germany using the $6 \mathrm{MV}$ photon energy). Patients were fixed in a custom-designed immobilization device (a thermoformed mask) and treated in supine or prone position, depending on tumor location. Lateral opposed fields were used only when extensive bilateral tumor involvement was present. Lateral and vertex (or angled vertex) fields in a wedge-pair arrangement were used for lateral lesions, while a 3-field approach for more midline tumors. The initial PTV encompassed the enhancing lesion (GTV) and edema (CTV) with a $2.5-\mathrm{cm}$ margin. The conventional dose schedule was 59.4 Gy given in 33 daily fractions of $1.8 \mathrm{~Gy} /$ day, 5 days a week in 6.6 weeks total treatment time. After $45 \mathrm{~Gy}$, the PTV was reduced to include only the enhancing lesion with a $2.5-\mathrm{cm}$ margin $(2.5 \mathrm{~cm}$ around the T1 contrast in MR-images). All fields were treated daily with a $2 \mathrm{D}$ treatment planning graph and an isocentric technique (dose calculation at the $90 \%$ isodose line). Portal imaging or simulation films to verify RT-fields were taken every second week. RT was initiated between $30 \mathrm{~min}$ and $2 \mathrm{~h}$ after topotecan infusion.

Topotecan (Hycamptin) was supplied, by GlaxoSmithKline Pharmaceutical in vials containing $4 \mathrm{mg}$ of lyophilized powder; this, was reconstituted with $4 \mathrm{ml}$ of sterile water for injection before dilution with $0.9 \%$ sodium chloride or $5 \%$ dextrose. The MTD of topotecan administered as a single 
Table I. Patient and disease characteristics.

\begin{tabular}{|c|c|c|}
\hline \multirow[b]{2}{*}{ Characteristic } & \multicolumn{2}{|c|}{ GM patients } \\
\hline & No. & $(\%)$ \\
\hline No. of patients & 36 & \\
\hline \multicolumn{3}{|l|}{ Age (years) } \\
\hline$<50$ & 17 & 47 \\
\hline$\geq 50$ & 19 & 53 \\
\hline Mean & 56.7 & \\
\hline Range & $21-76$ & \\
\hline \multicolumn{3}{|l|}{ Sex } \\
\hline Male & 23 & 63.8 \\
\hline Female & 13 & 36.2 \\
\hline \multicolumn{3}{|l|}{ Performance status (PS) } \\
\hline $\mathrm{WHO}=0$ & 21 & 58.3 \\
\hline $\mathrm{WHO}=1$ or 2 & 15 & 41.6 \\
\hline \multicolumn{3}{|l|}{ Prior surgery } \\
\hline Biopsy & 11 & 30.6 \\
\hline Total resection & 7 & 19.4 \\
\hline Partial resection & 18 & 50 \\
\hline \multicolumn{3}{|l|}{ Neurological function } \\
\hline No symptoms & 7 & 19.4 \\
\hline Normal functions & & \\
\hline Minor symptoms & 14 & 38.8 \\
\hline Minor mental confusion & & \\
\hline Moderate/fully active & 12 & 33.3 \\
\hline Moderate/not fully active & 3 & 8.3 \\
\hline Gross confusion & & \\
\hline \multicolumn{3}{|l|}{ Time from first symptoms } \\
\hline$<3$ months & 25 & 69 \\
\hline$\geq 3$ months & 11 & 31 \\
\hline \multicolumn{3}{|l|}{ Anticonvulsive treatment } \\
\hline Valproid acid & 15 & 69 \\
\hline Phenyntoin & 21 & 31 \\
\hline
\end{tabular}

agent in studies of recurrent GM (11) or in trials of concurrent chemoradiotherapy (CCRT) $(17,18)$ has been reported to be $1.5 \mathrm{mg} / \mathrm{m}^{2} / \mathrm{d}$ for 5 days repeated in 3 week intervals. The drug was administered intravenously by $30-\mathrm{min}$ infusion before radiotherapy on days D1, D8, D15, D22, D29, D36, D43 and D4, D11, D18, D25, D32, D39, D46 respectively. The rationale for this approach is that more frequent administration of moderate doses of the drug may achieve greater efficacy than higher doses every 3 weeks, through a more sustained exposure of dividing tumor cells to cytotoxic drug levels. As a consequence, patients should benefit from both a greater dose intensity and higher cumulative doses, while the lower individual doses could be less toxic (19). Despite the knowledge from preclinical and clinical results $(9,13)$ suggesting that topotecan activity was greatest when given continuously over a prolonged period of time, i.v. continuous infusions from $24 \mathrm{~h}$ to 21 days were not used due to the difficulties regarding the availability of the port system and the outpatient based standards of our department. The final topotecan concentration was determined by the dose level studied and by the patient body surface area.

There were three dose levels for topotecan administration. The initial dose of level III was $1.5 \mathrm{mg} / \mathrm{m}^{2} / \mathrm{d}$ given twice a week (biw) and the decrease of further levels was by $0.25 \mathrm{mg} /$ $\mathrm{m}^{2}$, so that the level II consisted of $1.25 \mathrm{mg} / \mathrm{m}^{2} / \mathrm{d}$, biw and the level I of $1.0 \mathrm{mg} / \mathrm{m}^{2} / \mathrm{d}$, biw, respectively. The number of patients selected in each group was a random event. We started treating patients with the higher topotecan dose and a greater number of cases was used at level III on the belief that the patients could tolerate more efficacious treatment according to the RTOG data $(20,21)$.

Definition of DLT and MTD. The DLTs were assessed during the whole duration of CCRT and for the following 4 weeks after treatment completion. A DLT was defined as the occurrence of any of the following: i) grade 3/4 leucopenia and/or thrombocytopenia and ii) any non-hematological toxicity grade 3 or more, such as vomiting, nausea, fever/infection, cutaneous erythema, diarrhea, confusion, not resolving to grade 1-2 within 2 days or grade $3 / 4$ asthenia in at least $50 \%$ of patients found in the 3 dose groups, iii) any adverse event confirmed to interrupt CCRT for $>1$ week in $50 \%$ of the patients treated in each of the 3 dose level groups. When a DLT occurred, chemotherapy was suspended until the return of a grade 1 toxicity state, and then continued at a lower dose level. Chemotherapy was stopped if DLT reoccurred or in case of a severe side-effect; however RT was continued until the end of the CCRT schedule. The topotecan dose immediately before the level at which the DLT was observed was the MTD or the recommended dose.

\section{Results}

Patient demographics. Between July 2001 and July 2006, 36 naïve patients with histologically confirmed GM were enrolled in the study; 33 of the patients had GM and 3 had a mixed anaplastic (grade 3 ) and grade 4 histology. The median age was 56.7 years (range 21-76 years). Additional characteristics, performance status, grading and resectability are shown in Table I. All patients were evaluated for toxicity. On early postoperative MRI, no residual tumor was seen in 7 patients who had total resection of the brain tumor. Methylprednizolone $(16 \mathrm{mg}$ ) was given qd or bid during the whole period of CCRT. A total of 14 cycles of topotecan were administered for every patient. All the cases received the dose of the drug, i.v., according to the protocol every Monday and Thursday or Tuesday and Friday each week of external-beam therapy. Chemotherapy was withheld until the WBC count was $>3,000$ cells $/ \mathrm{mm}^{3}$ and platelet count was $>100,000$ cells/ $\mathrm{mm}^{3}$. Radiotherapy was withheld for grade 3 or 4 hematologic toxicity. A month later after CCRT completion all the patients continued their treatment with the PVC chemotherapy regimen until disease deterioration, and then to temozolomide orally, as second line treatment. 
Table II. Myelotoxicity and CCRT delays.

No. of patients per toxicity grades 2-4 in each of the three dose level groups

Topotecan dose level

twice a week

$1.0 \mathrm{mg} / \mathrm{m}^{2}+\mathrm{RT}$

$1.25 \mathrm{mg} / \mathrm{m}^{2}+\mathrm{RT}$

$1.5 \mathrm{mg} / \mathrm{m}^{2}+\mathrm{RT}$

No. of patients

10

11

15

Toxicity grade

2

3

Anemia

Leucopenia

Neutropenia

Febrile neutropenia

Thrombocytopenia

Platelet transfusion

Treatment delays
2

1
2

2 2

1

2 patients

(1 week)
3

$1^{\mathrm{a}}$

$1^{\mathrm{a}}$

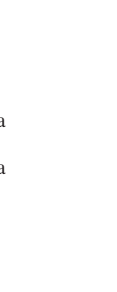

4

2

2

3

3

1

$1^{\mathrm{b}}$

3 patients

1 week/1 patient

2 weeks/2 patients

${ }^{a}$ The same patient treated at the $1.25 \mathrm{mg} / \mathrm{m}^{2}$, twice a week topotecan dose level. ${ }^{\mathrm{b}}$ One of the two patients with G4 neutropenia also had platelet G3 toxicity and was admitted in the hospital due to febrile neutropenia.

Dose limiting toxicities (DLTs). Tables II and III show the topotecan dose-escalation levels, the number of patients enrolled at each level, the observed DLTs during treatment and the CCRT delays which are summarized in Tables IV and V. DLTs were only hematological. Ten patients were enrolled at level I (topotecan $1.0 \mathrm{mg} / \mathrm{m}^{2} / \mathrm{d}$, biw). No grade 4 leucopenia or thrombocytopenia was observed. Grade $2 / 3$ (G2/3) hematologic toxicity was observed in 4 cases. Eleven patients accrued to level II (topotecan dose $1.25 \mathrm{mg} / \mathrm{m}^{2} / \mathrm{d}$, biw). One patient had G3 thrombocytopenia and three presented with G 2/3 leucopenia (1 G3 neutropenia). For the patients with G3 toxicity (1 with neutropenia and 1 with thrombocytopenia), 5-day treatment interruption was allowed for CCRT continuation. Fifteen cases accrued at level III (topotecan dose $1.5 \mathrm{mg} / \mathrm{m}^{2} / \mathrm{d}$, biw). Six of these patients had episodes of grade 3/4 leucopenia and 2 developed grade 4 thrombocytopenia. Thus, 8 patients out of 15 treated at the 3 rd level presented with G4 hematologic sequelae. One out of two patients with G4 neutropenia also had platelet G3 toxicity and was hospitalized due to febrile neutropenia. Platelet (PTL) transfusions were necessary for one patient with G4 thrombocytopenia who was admitted due to more than 7-day duration of WBC/PTL toxicity. One and 2-week treatment delay was allowed in one (ANC, G4) and two (ANC, G4 and PTL, G4) patients respectively due to G4 hematologic toxicity. Given the observed results at the first (no DLTs) and third ( 8 occurrences of DLTs) patient groups, the DLT's topotecan dose level was reached at the $1.5 \mathrm{mg} / \mathrm{m}^{2}$ twice a week schedule; thus, the recommended MTD dose was found as $1.25 \mathrm{mg} / \mathrm{m}^{2}$ given twice weekly concurrently with external RT along with 6.6-8.6 weeks total treatment time (1 and 2 weeks RT delay due to hematologic toxicity in 3 and 2 patients, respectively).
Non-dose limiting toxicity evaluation. No severe adverse effects were noted during the CCRT treatment or within the month following irradiation. At level I, we had one patient with $\mathrm{G} 3$ anemia $(\mathrm{Hb}=6.5-7.9 \mathrm{~g} / \mathrm{dl}), 2$ with $\mathrm{G} 2$ leucopenia, one with G1 thrombocytopenia, two patients with G2 nausea/ vomiting, one with G2 weight loss, two with G2 confusion, and 1 with altered taste. All cases with anemia were restored with blood transfusion on an out patient basis combined with HuEPO s.c. injections for an optimal Hb level $\geq 12.5 \mathrm{~g} / \mathrm{dl}$, during the whole course of CCRT. At level II, two patients presented with $\mathrm{G} 2$ anemia $(\mathrm{Hb}=8-10 \mathrm{~g} / \mathrm{dl})$, two with $\mathrm{G} 2 / 3$ nausea/vomiting, one with G3 asthenia and one with pulmonary thromboembolism (G3 toxicity). This last sideeffect occurred during the fifth week of CCRT in a patient who was hospitalized for one week. Chemotherapy was interrupted, fraxiparine was administered s.c., and 7-day treatment delay was allowed for RT continuation. The remaining side-effects (diarrhea, anorexia, cutaneous erythema, headache, insomnia, seizures) are shown in Table III. One week treatment delay was necessary for the patient with G3 asthenia treated at the second topotecan dose level who also had G3 neutropenia and another week was given for the patient with G3 thrombocytopenia (Table IV). At level III, febrile neutropenia occurred in one patient (ANC, G4 plus G4 thrombocytopenia) and restored with hospital admission and antibiotics. Hematologic toxicity plus asthenia G3 were responsible for 1 - and 2-week treatment delays in 2 out of 15 patients treated $1.5 \mathrm{mg} / \mathrm{m}^{2} / \mathrm{d}$, biw topotecan dose level (one patient with ANC, G4 plus G3 asthenia - 1 week and one patient with PTL, G4 toxicity - 2 weeks) (Table IV). Erythema of the skin, diarrhea, headache, insomnia, seizures and lightheadedness most of grade 2 were also reported. In total, 394 cycles of chemotherapy were administered simultaneously with 
Table III. Main non-hematologic toxicities.

No. of patients per toxicity grades 2-4 in each of the three dose level groups

\begin{tabular}{|c|c|c|c|c|c|c|c|c|c|}
\hline $\begin{array}{l}\text { Topotecan dose level } \\
\text { twice a week }\end{array}$ & & $1.0 \mathrm{mg} / \mathrm{m}^{2}+\mathrm{RT}$ & & & $\mathrm{g} / \mathrm{m}$ & & & $1.5 \mathrm{mg} / \mathrm{m}^{2}+\mathrm{RT}$ & \\
\hline No. of patients & & 10 & & & 11 & & & 15 & \\
\hline Toxicity grade $(\mathrm{G})$ & 2 & 3 & 4 & 2 & 3 & 4 & 2 & 3 & 4 \\
\hline $\begin{array}{l}\text { Fever/Infections } \\
\text { (not associated with } \\
\text { neutropenia) }\end{array}$ & 1 & & & & & & & & \\
\hline Cutaneous/Erythema & & & & 1 & & & 2 & & \\
\hline Nausea/Vomiting & 2 & & & 1 & 1 & & 1 & 2 & \\
\hline Diarrhea & & & & 1 & & & 2 & & \\
\hline Asthenia/Fatigue & & & & & 1 & & 2 & 2 & \\
\hline Weight loss & 1 & & & & & & 2 & & \\
\hline Pulmonary embolism & & & & & $1^{\mathrm{a}}$ & & & & \\
\hline Confusion & 2 & & & & 1 & & 1 & 1 & \\
\hline Seizure & & & & 2 & & & 2 & & \\
\hline Headache & 2 & 2 & & 1 & 2 & & 2 & & \\
\hline Insomnia & 1 & & & & 1 & & 3 & & \\
\hline Anorexia & & & & & 3 & & & 2 & \\
\hline Altered taste & 1 & & & & & & 2 & & \\
\hline Lightheadedness & & & & & & & 1 & & \\
\hline Treatment delay & & & & & $\begin{array}{l}\text { atier } \\
\text { blism } \\
\text { pital } \\
1 \mathrm{w}\end{array}$ & & & & \\
\hline
\end{tabular}

concurrent external RT. A median of 13.83 cycles of chemotherapy were given per patient. During the 5th and 6th week of CCRT, chemotherapy was inter-rupted in one patient with pulmonary embolism while, four were transferred to lower dose levels of topotecan respectively. A dose reduction by one level (from level III to level II) was required in 2 patients and from level II to level I in 2 more patients due to grade $3 / 4$ hematologic toxicity and asthenia as well. There were four patients with 1 - (2 cases) and 2-week (2 patients) treatment interruption, respectively (Table IV). Chemotherapy was permanently abandoned only for the patient with lung embolism, also due to his PS deterioration.

\section{Discussion}

In this phase I clinical trial, we investigated the feasibility and toxicity of a concurrent chemoradiotherapy (CCRT) regimen with topotecan. Many authors have described the feasibility of concomitant chemoradiation in patients with glioblastoma multiforme (GM). There are some studies referring to simultaneous chemoradiotherapy of GM with topotecan in adults (20-28) and in children (29-31). Myelosuppression, especially neutropenia and thrombocytopenia were the DLTs. Both the daily x 5 regimen $(11,20,21)$ and the continuous i.v. infusion one $(23,25,28)$ comprised of a 6 week course of topotecan at a dose of $0.4-0.5 \mathrm{mg} / \mathrm{m}^{2} / \mathrm{d}$ for 21 days, had been used, but no phase III studies exist to compare the possible clinical superiority of the continuous infusion over bolus injection. The most important determinant of cytotoxicity with topotecan, based on preclinical data in vitro and in vivo appears to be duration of exposure, supported by early studies which have confirmed that prolonged exposure seemed superior to intermittent treatment (32). Recently, clinical trials in ovarian cancer, lung cancer and other malignancies have started to evaluate the feasibility and toxicity of an alternative scheme of topotecan administration on a weekly basis (33-35). The potential benefits of this schedule include better tolerability, reduced toxicity and greater patient convenience or quality of life (19). No data of weekly or biweekly administration of CCRT with topotecan in GM patients exist. On the contrary, weekly administration of topotecan in NSCLC, ovarian cancer patients or in other malignancies was well tolerated at doses escalated from 1.5 to $2.25 \mathrm{mg} / \mathrm{m}^{2}$ (35) up to $4 \mathrm{mg} / \mathrm{m}^{2}$ for reaching effectiveness in untreated ovarian cancer patients $(33,34)$. At the $1.5 \mathrm{mg} /$ $\mathrm{m}^{2} / \mathrm{d}$ x 5 days schedule, Fisher et al reported the results of a phase I (RTOG 9507) and a phase II (RTOG 9513) trial of topotecan plus cranial RT $(20,21)$. In contrast to our study, 
Table IV. Dose limting toxicities (DLTs) per topotecan dose level for the glioblastoma multiform (GM) of the brain patients treated with concurrent chemotherapy (topotecan) and external irradiation (CCRT).

\begin{tabular}{|c|c|c|c|c|c|c|}
\hline \multirow[b]{2}{*}{$\begin{array}{l}\text { Topotecan } \\
\text { dose level }\end{array}$} & \multirow[b]{2}{*}{ Patients } & \multirow[b]{2}{*}{$\begin{array}{l}\text { Patients with } \\
\text { DLTs (n) }\end{array}$} & \multirow[b]{2}{*}{$\begin{array}{c}\text { DLTs } \\
\text { patients (n) }\end{array}$} & \multicolumn{3}{|c|}{ Concurrent chemoradiotherapy delays } \\
\hline & & & & $\begin{array}{l}\text { Toxicity } \\
0 \text { Days }\end{array}$ & $\begin{array}{l}\text { Patients (n) } \\
\text { 3-7 Days }\end{array}$ & 8-14 Days \\
\hline $\begin{array}{l}\text { Level I } 1.0 \mathrm{mg} / \mathrm{m}^{2} / \mathrm{d} \\
\text { twice per week }\end{array}$ & 10 & - & - & - & - & - \\
\hline $\begin{array}{l}\text { Level II } 1.25 \mathrm{mg} / \mathrm{m}^{2} / \mathrm{d} \\
\text { twice per week }\end{array}$ & 11 & $3 / 11$ & $\begin{array}{l}\text { G3 leucopenia, (1) } \\
\text { G3 neutropenia }(1)^{\mathrm{a}} \\
\text { G3 thrombocytopenia, (1) } \\
\text { G3 asthenia, (1) }{ }^{\mathrm{a}} \\
\text { Lung embolism (1) }\end{array}$ & - & $\begin{array}{l}\text { G3 ANC, (1) }{ }^{\mathrm{a}} \\
\text { G3 PTL, (1) } \\
\text { G3 asthenia, (1) } \\
\text { Lung embolism (1) }\end{array}$ & - \\
\hline $\begin{array}{l}\text { Level III } 1.5 \mathrm{mg} / \mathrm{m}^{2} / \mathrm{d} \\
\text { twice per week }\end{array}$ & 15 & $3 / 15$ & $\begin{array}{l}\text { G3/4 leucopenia, (6) } \\
\text { G3 neutropenia, (1) } \\
\text { G4 neutropenia (2) } \\
\text { G4 thrombocytopenia, (2) } \\
\text { G4 febrile neutropenia (1) } \\
\text { G2 asthenia, (1) } \\
\text { G3 asthenia (2) }\end{array}$ & - & $\begin{array}{l}\text { G4 ANC G4 }(1)^{\mathrm{b}} \\
\text { G3 asthenia }(1)^{\mathrm{b}}\end{array}$ & $\begin{array}{l}\text { PTL G4 }(2)^{\mathrm{c}} \\
\text { Febrile } \\
\text { neutropenia }(1)^{\mathrm{c}}\end{array}$ \\
\hline Total & 36 & & & & 3 patients & 2 patients \\
\hline
\end{tabular}

Table V. Overall adverse events of 36 patients treated with topotecan and concurrent RT for a median duration of treatment of 7 weeks (range, 6.6-8.6 weeks).

\begin{tabular}{|c|c|c|c|c|c|c|}
\hline \multirow[b]{2}{*}{ Toxicity } & \multicolumn{2}{|c|}{ Grade 2 patients } & \multicolumn{2}{|c|}{ Grade 3 patients } & \multicolumn{2}{|c|}{ Grade 4 patients } \\
\hline & (n) & $(\%)$ & $(\mathrm{n})$ & $(\%)$ & $(\mathrm{n})$ & $(\%)$ \\
\hline \multicolumn{7}{|l|}{ Hematologic toxicity } \\
\hline Anemia & 4 & 11 & 1 & 2.7 & - & \\
\hline Leucopenia & 4 & 11 & 4 & 11 & 3 & 8.3 \\
\hline Neutropenia & - & & 2 & 5.5 & 2 & 5.5 \\
\hline Febrile neutropenia & - & & - & & 1 & 2.7 \\
\hline Throbocytopenia & 1 & 2.7 & 2 & 5.5 & 2 & 5.5 \\
\hline \multicolumn{7}{|l|}{ Non-hematologic toxicity } \\
\hline Nausea/Vomiting & 4 & 11 & 3 & 8.3 & - & \\
\hline Anorexia & - & & 5 & 13.8 & - & \\
\hline Altered taste & 3 & 8.3 & - & & - & \\
\hline Weight loss & 3 & 8.3 & & & & \\
\hline Asthenia/Fatigue & 2 & 5.5 & 3 & 8.3 & - & \\
\hline Headache & 5 & 13.8 & 4 & 11 & - & \\
\hline Insomnia & 4 & 11 & 1 & 2.7 & - & \\
\hline Lightheadness & 1 & 2.7 & - & & - & \\
\hline Confusion & 3 & 8.3 & 2 & 5.5 & - & \\
\hline Seizure & 4 & 11 & - & & - & \\
\hline Cutaneous erythema & 3 & 8.3 & & & & \\
\hline Fever/Infections & 1 & 2.7 & & & & \\
\hline Pulmonary thromboembolism & - & & 1 & 2.7 & & \\
\hline
\end{tabular}


they administered topotecan as a short (30 min) infusion daily for 5 days, at 21-day intervals commencing at day 1 of RT. The topotecan dose was escalated in 3-dose increments from 0.5 (level 1) to 1.0 (level 2) and to $1.5 \mathrm{mg} / \mathrm{m}^{2} / \mathrm{d}$ (level 3) in different patient groups. Hematologic toxicity increased as the dose of topotecan increased, according to our results. One G3 neutropenia occurred at level 1, out of 15 patients. Five of 17 patients treated at level $2\left(1.0 \mathrm{mg} / \mathrm{m}^{2} / \mathrm{d}\right.$ x 5 days $)$ had $\mathrm{G} 4$ neutropenia, one of whom grade 4 leukopenia lasting less than 7 days. In addition, there were nine grade 3 hematologic toxicities. In our study at the $1.0 \mathrm{mg} / \mathrm{m}^{2}$ twice a week level, no grade $3 / 4$ leucopenia or neutropenia occurred, while at the $1.25 \mathrm{mg} / \mathrm{m}^{2}$ level, 3 out of 11 patients had grade $2 / 3$ leucopenia, (1 G4 neutropenia) and one had G3 thrombocytopenia. In the RTOG 9507 trial, 8 of 17 patients accrued at level $3\left(1.5 \mathrm{mg} / \mathrm{m}^{2} / \mathrm{d}\right.$ x 5 days $)$ had brief G4 neutropenia lasting less than 7 days and 4 had G3 thrombocytopenia. One patient had a break in RT treatment and none of the G3/4 neutropenias were associated with fever. In our study, 3 out of 15 patients treated at the $1.5 \mathrm{mg} / \mathrm{m}^{2}$, biw schedule, experienced treatment delay ( 1 week for one patient and 2 weeks for 2 patients). This dose level gives in total $19.8 \mathrm{mg} / \mathrm{m}^{2}$ in 6.6 weeks treatment time for $5940 \mathrm{cGy}$ of external RT, conventionally fractionated $(1.8 \mathrm{~Gy} / \mathrm{d}, 5$ days a week). In the RTOG trials, topotecan was administered i.v., 0.5-2 h before RT on days $1-5,22-26$, and 43-47 i.e., $1.5 \mathrm{mg} / \mathrm{m}^{2} / \mathrm{d}$ x 5 days every 3 weeks for a total of 3 cycles. Considering only 2 cycles of the above regimen to compare our results with the RTOG results (60 Gy in 6 weeks CCRT treatment time), the $1.0 \mathrm{mg} / \mathrm{m}^{2} / \mathrm{d}$ x 5 days and the $1.5 \mathrm{mg} / \mathrm{m}^{2} / \mathrm{d}$ x 5 days RTOG programs give in total 10 and $15 \mathrm{mg} / \mathrm{m}^{2}$ of topotecan, respectively. The RTOG hematologic sequelae at the above dose levels are comparable to that of our own at the 1.25 and $1.5 \mathrm{mg} / \mathrm{m}^{2} / \mathrm{d}$, twice a week regimen which give in total 16.5 and $19.8 \mathrm{mg} / \mathrm{m}^{2}$ of topotecan respectively in 6.6 weeks treatment time. That is, by using the weekly schedule, greater topotecan doses can be given concurrently with RT with roughly the same hematologic toxicity (higher antitumor activity with larger topotecan doses, keeping the main CCRT sequelae in standard non-prohibitive levels).

In our study, no cognitive testing was done to evaluate neurological late toxicity at 21 months (range 6-36) median follow-up time; however, no early severe neurological CCRT sequelae were reported, suggesting that topotecan does not increase RT toxicity. This is in accordance with two aforementioned trials $(11,20)$.

Previous studies of CCRT with continuous infusion (c.i.) of topotecan $0.3-0.8 \mathrm{mg} / \mathrm{m}^{2} / \mathrm{d}, \mathrm{d} 1-21$ (25-27) or c.i. on weeks 1,3 and 5 during RT (23) have been published. Klautke et al (25) used hyperfractionated accelerated RT with c.i. of topotecan $0.5 \mathrm{mg} / \mathrm{m}^{2} / \mathrm{d}$, days $1-21$ (5725 cGy in 3 weeks treatment time). Hematological toxicities were 13/42 (30\%) G3 and 2/42 (4\%) G4 leucopenia, as well as 5/42 (10\%) G3 and $1 / 42(2 \%) \mathrm{G} 4$ thrombocytopenia respectively. Grabenbauer et al (27) by treating 20 patients with the above CCRT schedule (topotecan $0.3-0.8 \mathrm{mg} / \mathrm{m}^{2} / \mathrm{d}$ during 21 days concomitantly with cranial RT), found G3/4 hematologic toxicity in $17 \%$ of the cycles. In addition, Lesimple et al (23) treated 21 patients with conventional RT (60 Gy/30 fractions/40 days) and 3 cycles of c.i. topotecan from day 1-5 on weeks 1, 3 and 5 during RT. By escalating the dose from 0.6 to $1.0 \mathrm{mg} / \mathrm{m}^{2} / \mathrm{d}$, in 4 dose levels, they found DLTs in 5 out of 21 patients $(23.8 \%)$, including 4 G4 thrombocytopenia, 2 G4 neutropenia (1 of more than 7 days) and 1 platelet transfusion. The above data compare favorably with that of our own [1 G3 anemia, 7/36 G3/4 leucopenia (19.4\%), 2/36 G4 thrombocytopenia (5.5\%)]. Furthermore, CCRT was performed conventionally fractionated $(60 \mathrm{~Gy})$ with $0.5 \mathrm{mg}$ (absolute dose) of topotecan, i.v., every day $1 \mathrm{~h}$ prior to RT resulting in a cumulative dose of $15 \mathrm{mg}$, in two studies $(22,24)$. Toxicity G3/4 occurred in 9 out of 57 patients (15.8\%); two were hematologic, three with motoric disorders, one esophagitis, one infection, one nausea, and one mental disorder. It seems that the CCRT regimen used from the German authors (Philips University of Marburg, Germany) in the aforementioned trials offers the best advantage regarding treatment effectiveness, reduced toxicity, greater patient convenience and quality of life, for treating GM cases on an out-patient basis. The above thesis was also supported by the children's Cancer Group $(30,31)$ and by the French Society of Pediatric Oncology (29); they all tried to maximize the number of intermittent injections of topotecan by infusing the drug at a dose of $0.4 \mathrm{mg} / \mathrm{m}^{2} / \mathrm{d}$, over $30 \mathrm{~min}$ within $1 \mathrm{~h}$ before RT for 33 days in phase I studies with brainstem/pontine glioma patients.

Maximal radiosensitization by topoisomerase-I (topo-I) inhibitors occurs during or immediately after RT (15). Blaney et al (9) examined the plasma and CSF pharmacokinetics of topotecan in non-human primates; they found peak CSF concentrations $30 \mathrm{~min}$ after injections. Administration of the drug more than $30 \mathrm{~min}$ before RT would allow for decay of these peak topotecan CSF levels (9). Although Danks et al (36) reported that intermittent exposure to topotecan produces growth inhibition equivalent to continuous exposure, there are some reasons supporting that large number of intermittent injections or continuous infusion (c.i.) are superior to bolus injections. The cytotoxicity of camptothecins is dependent on the formation of topo-I/DNA complexes during the S-phase of the cell cycle; c.i. or more frequent (twice or 5 days per week) i.v. injections can increase cell death by permitting a greater number of tumor cells to enter $\mathrm{S}$-phase when the drug is present. The above modes of topotecan administration can provide constant exposure to the drug during RT, acting as permanent radiosensitizer, potentially maximizing antitumor activity and CSF penetration, and at the same time offering reduced hematologic toxicity.

We started the above CCRT trial with GM patients by using topotecan on a twice a week schedule because of the existing experience (37-40) and the absence of a Radiotherapy Clinic in our Hospital.

No evidence could be presented that the above protocol (The Kaplan Meier, Relapse-Free Survival and Overall Survival curves are under investigation) is at least as effective as: i) the RTOG 9507/9513 phase I/II trials $(20,21)$, ii) the concomitant treatment with topotecan as continuous infusion $(25,27)$, and iii) the every day, i.v., regimen, 30-60 min before irradiation (22,24,29-31). This merits further evaluation in phase III trials. A phase II trial is ongoing in our department to establish the response rates, the local failures and the median survival of the above patients. 


\section{Acknowledgements}

The authors thank GlaxoSmithKline for their constant contribution towards the scientific work of the Department of Radiotherapy and Oncology, University Hospital of Heraklion.

\section{References}

1. Fine H, Barker F, Markett $\mathbf{J}$ and Loeffler $\mathrm{J}$ : Neoplasms of the CNS. In: Cancer Principles and Practice of Oncology. 7th edition. De Vita VT, Hellman S and Rosenberg SA (eds). Lippincott Williams \& Wilkins, pp1834-1887, 2005.

2. Westphal M, Lamszus K and Hilt D: Intracavitary chemotherapy for glioblastoma: present status and future directions. Acta Neurochir 88: 61-67, 2003.

3. Bleehan N, Stenning S and MRC Brain Tumor Working Party: A Medical Research Council trial of two radiotherapy doses in the treatment of grades 3 and 4 astrocytoma. Br J Cancer 64: 769-774, 1991.

4. Glioma Meta-Analysis Trialists (GMT) Group: Chemotherapy in adult high-grade glioma: a systematic review and metaanalysis of individual patient data from 12 randomized trials. Lancet 359: 1011-1018, 2002.

5. Rampling R: Chemotherapy: determining the appropriate treatment. In: Improving Care of Patients With Malignant Glioma. Davies EH and Hopkins A (eds). London: Royal College of Physicians, pp63-74, 1997.

6. Pan E and Prados M: Primary Neoplasms of the CNS. In: Cancer Medicine 6. Holland-Frei, BC Decker Inc., pp1195-1226, 2003.

7. Stupp R, Mason W, van den Bent M, Weller M, Fisher B, Taphoorn M, Brandes A, Cairncross G, Lacombe D and Mirimanoff R: Concomitant and adjuvant temozolamide and radiotherapy for newly diagnosed glioblastoma multiforme. Conclusive results of a randomized phase III trial by the EORTC Brain and RT Groups and NC/C Clinical Trials Group. Proc ASCO 23: abs. 2, 2004.

8. Eng W, Faucetter L, Johnson RK and Sternglanz R: Evidence that DNA topoisomerase I is necessary for the cytotoxic effects of camptothecins. Mol Pharmacol 34: 755-760, 1988.

9. Blaney S, Cole D, Balis F, Gadwin K and Poplack D: Plasma and cerebrospinal fluid pharmokinetic study of topotecan in non-human primates. Cancer Res 53: 725-727, 1993.

10. Friedman H, Houghton P, Schold S, Keir S and Bigner D: Activity of 9-dimithylaminoethyl-10-hydroxicamptothecin against pediatric and adult CNS tumor xenografts. Cancer Chemo Pharma 34: 171-174, 1994.

11. MacDonald D, Cairncross G, Stewart D, Forsyth P, Sawka C, Wainman $\mathrm{N}$ and Eisenhauer E: Phase II study of topotecan in patients with recurrent malignant glioma. NCI of Canada Clinical Trials Group. Ann Oncol 7: 205-207, 1996.

12. Friedman H, Kerby T, Fields S, Zilisch J, Graden D, McLendon R, Houghton P, Arbuck S, Cokgor I and Friedman A: The Brain Tumor Center at Duke. Topotecan treatment of adults with primary malignant glioma. Cancer 85: 1160-1165, 1999.

13. Heron JF: Topotecan: an oncologist's view. Oncologist 3: 390-402, 1998.

14. Rich $\mathrm{T}$ and Karichenko A: Camptothecin radiation sensitization mechanisms, schedules and timing. Oncology 12: 114-120, 1998.

15. Lamond J, Metha M and Boothman D: The potential of topoisomerase-I inhibitors in the treatment of CNS malignancies. Report of a synergistic effect between topotecan and radiation. J Neurooncol 90: 1-6, 1996.

16. National Cancer Institute. Cancer Therapy Evaluation Program. Common Toxicity Criteria Manual, Version 2.0. June 1, NCI CTEP Help Desk, 1999.

17. Verweij J, Lund B, Beynen J, et al: Clinical studies with topotecan. The EORTC experience. Proceedings of the 7th NCIEORTC symposium on new drugs in cancer therapy. Ann Oncol 3: p118, 1992.

18. Rowinsky E, Grochow LB, Hendricks CB, Ettinger DS, Forastiere AA, Hurowitz LA, McGuire WP, Sartorius SE, Lubejko BG, Kaufmann SH and Donehower RC: Phase I and pharmacologic study of topotecan: a novel topoisomerase I inhibitor. J Clin Oncol 10: 647-656, 1992.
19. Rowinsky EK: Weekly topotecan. An alternative to topotecan's standard daily x 5 schedule? Oncologist 7: 324-330, 2002.

20. Fisher BJ, Scott C, MacDonald DR, Coughlin C and Curran WJ: Phase I study of topotecan plus cranial radiation for glioblastoma multiforme: results of radiation therapy oncology group trial 9507. JCO 19: 1111-1117, 2001.

21. Fisher BJ, Won M, David MacDonald D, Johnson DW and Roa W: Phase II study of topotecan plus cranial radiation for glioblastoma multiforme: results of Radiation Therapy Oncology Group 9513. Int J Rad Onc Biol Phys 53: 980-986, 2002.

22. Gross MW, Altscher R, Brantner M, Haeusser-Mischlich H, Chiricuta IC, Siegmann AD and Engenhart-Cabillic R: Openlabel simultaneous radio-chemotherapy of glioblastoma multiforme with topotecan in adults. Clin Neurol Neurosurg 107: 207-213, 2005.

23. Lesimple T, Hassel MB, Gedouin D, Seigneuret E, Carsin B, Hamlat A, Riffaud L, Simon H, Malhaire JP and Guegan Y: Phase I study of topotecan in combination with concurrent radiotherapy in adults with glioblastoma. J Neurooncol 65: 141-148, 2003.

24. Gross MW, Altscher R, Brandtner M, Hausser-Mischlich H, Kiricuta IC, Siegmann AD and Engenhart-Cabillic R: Acute toxicity and changes in quality of life during a combined radiochemotherapy of glioblastomas with topotecan (Hycamtin). Strahlenther Oncol 177: 656-661, 2001.

25. Klautke G, Schutze M, Bombor I, Benecke R, Piek J and Fietkau R: Concurrent chemoradiotherapy and adjuvant chemotherapy with Topotecan for patients with glioblastoma multiforme. J Neurooncol 77: 199-205, 2006.

26. Burch PA, Bernath AM, Cascino TL, Scheithauer BW, Novotny P, Nair S, Buckner JC, Pfeifle DM, Kugler JW and Tschetter LK: A North Central Cancer Treatment Group phase II trial of topotecan in relapsed gliomas. Invest New Drugs 18: 275-280, 2000.

27. Grabenbauer GG, Buchfelder M, Schrell U, Fahlbusch R, Sauer R and Staab HJ: Topotecan as a 21-day continuous infusion with accelerated 3D-conformal radiation therapy for patients with glioblastoma. Front Radiat Ther Oncol 33: 364-368, 1999.

28. Brock CS, Bower M, Evans H, et al: Phase II trial of topotecan as a continuous intravenous infusion in patients with high-grade gliomas. Ann Oncol 7: 635, 1996.

29. Bernier-Chastagner V, Grill J, Doz F, Bracard S, Gentet JC, Marie-Cardine A, Luporsi E, Margueritte G, Lejars O, Laithier V, Mechinaud F, Millot F, Kalifa C and Chastagner P: Topotecan as a radiosensitizer in the treatment of children with malignant diffuse brainstem gliomas: results of a French Society of Paediatric Oncology Phase II Study. Cancer 104: 2792-2797, 2005.

30. Snaghavi S, Krailo M, Needle M, et al: Topotecan, as a radiosensitizer, for brainstem glioma (BSG) of childhood: first report of CCG 0952, a phase I study. Proc Am Soc Ther Radiat Oncol 42: 357A2260, 1998.

31. Needle M, Mehta M, Krailo M, et al: Phase I study of topotecan as a radiosensitizer prior to daily involved field irradiation in children with intrinsic pontine glioma: a children's Cancer Group Study. Proc Am Soc Clin Oncol 18: $558 \mathrm{a}, 1999$.

32. Houghton PJ, Cheshire PJ, Hallman JD II, Lutz L, Friedman HS, Danks MK and Houghton JA: Efficacy of topoisomerase I inhibitors, topotecan and irinotecan, administered at low dose levels in protracted schedules to mice bearing xenografts of human tumors. Cancer Chemother Pharmacol 36: 393-403, 1995.

33. Vandenput I, Amant F, Neven P, Berteloot P, Leunen K and Vergote I: Effectiveness of weekly topotecan in patients with recurrent epithelial ovarian cancer. Int J Gynecol Cancer 17: $83-87,2007$

34. Safra T, Menczer J, Bernstein R, Shpigel S, Inbar MJ, Grisaru D, Golan A and Levy T: Efficacy and toxicity of weekly topotecan in recurrent epithelial ovarian and primary peritoneal cancer. Gynecol Oncol (In press).

35. Eckardt J: Single-agent chemotherapy for non-small cell lung cancer. Lung Cancer 41: 17-22, 2003.

36. Danks M, Pawlik C, Whipple D and Wolverton JS: Intermittent exposure of medulloblastoma to topotecan produces growth inhibition equivalent to continuous exposure. Clin Cancer Res 3: $1731-1738,1997$. 
37. Varveris H, Kachris S, Mazonakis M, Lyraraki E, Markouizou A, Karabekios S, Tzedakis A, Perisinakis K, Damilakis J and Vlachaki M: Pegylated liposomal doxorubicin given concurrently with conventional radiotherapy: a phase I doseescalating trial for patients with squamous cell carcinoma of head and neck and lung. Oncol Rep 12: 473-481, 2004.

38. Varveris H, Mazonakis M, Lyraraki E, Kachris S, Vlachaki M, Haldeopoulos D, Angelakis E, Panagiotidis J, Martavatzis N, Kagogeraki A, Vasilaki A and Koumantakis E: A pilot study of preoperative (MDR brachytherapy \pm external irradiation) given concurrently to Caelyx and CDDP for endometrial carcinoma. Radiother Oncol 56: S70, 2000.
39. Varveris H, Mazonakis M, Vlachaki M, Kachris S, Lyraraki E, Zoras O, Maris T, Froudarakis M, Velegrakis J, Perysinakis C, Damilakis J and Samonis G: A phase I trial of weekly docetaxel and cisplatinum combined to concurrent hyperfractionated radiotherapy for non-small cell lung cancer and squamous cell carcinoma of the head and neck. Oncol Rep 10: 185-195, 2003.

40. Varveris H, Kachris S, Mazonakis M, Lyraraki E, Petineli E, Varveris A, Fasoulaki A, Tzedakis A, Kouloulias V, Zolindaki A and Vlachaki M: Phase I/II trial of external irradiation plus medium-dose brachytherapy given concurrently to liposomal doxorubicin and cisplatin for advanced uterine cervix carcinoma. Strahlenther Onkol 182: 125-134, 2006. 